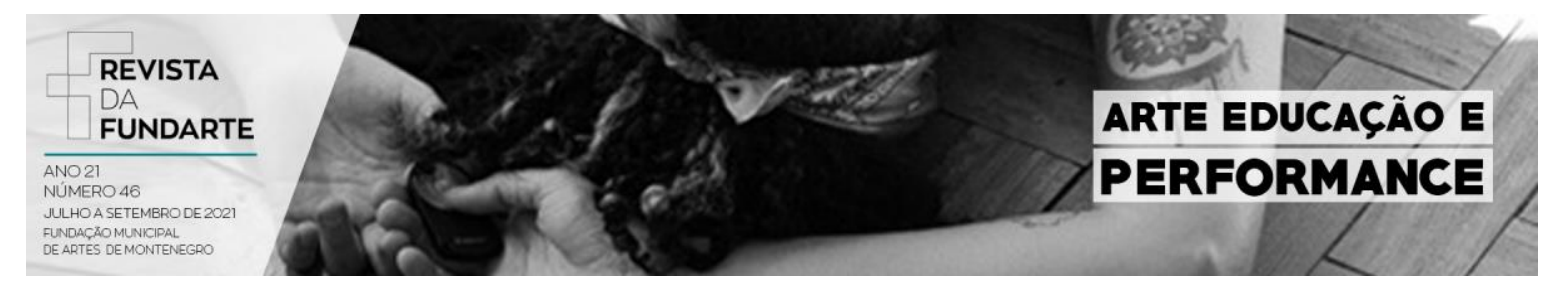

\title{
LABORAR A DOCÊNCIA ENTRE ESPERA E PRESENÇA: UM ESTUDO DA EDUCAÇÃO COMO PERFORMANCE ${ }^{1}$
}

Diego Winck Esteves

Máximo Daniel Lamela Adó

DOI: http://dx.doi.org/10.19179\%2F2319-0868.818

\footnotetext{
${ }_{1}^{1}$ Agência de fomento: Conselho Nacional de Desenvolvimento Científico e Tecnológico - CNPq. O presente trabalho foi realizado com apoio da Coordenação de Aperfeiçoamento de Pessoal de Nível Superior - Brasil (CAPES) - Código de Financiamento 001.

ESTEVES, Diego Winck; ADÓ, Máximo Daniel Lamela. Laborar a docência entre espera e presença: um estudo da educação como performance Revista da FUNDARTE. Montenegro, p.01-18, ano 21, no 46, setembro de 2021.

Disponível em: http://seer.fundarte.rs.gov.br/index.php/RevistadaFundarte/issue/archive $>30$ de setembro de 2021 .
} 


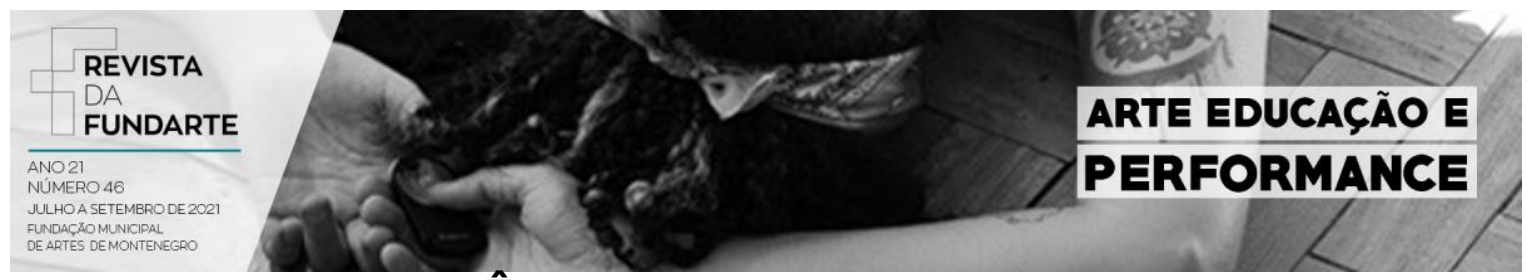

\title{
LABORAR A DOCÊNCIA ENTRE ESPERA E PRESENÇA: UM ESTUDO DA EDUCAÇÃO COMO PERFORMANCE ${ }^{2}$
}

Diego Winck Esteves ${ }^{3}$ Máximo Daniel Lamela Adó ${ }^{4}$

\begin{abstract}
Resumo: Este texto propõe perspectivar a docência pela via da performance, tendo em vista que certa noção de espera pode condicionar possibilidades para improvisações numa aula. Trata-se de postular a docência como um fazer que lida com acontecimentos. Todavia, nossa existência se desdobra sobre uma cultura de sentidos, na qual é preciso constituir condições para produzir presenças, visto que os sentidos se impõem a todo o momento. Conjecturamos a espera como este artifício. Trata-se de um jogo onde a performance docente age no limiar entre educação e arte, uma vez que se aloca na interlocução entre o visível e o imprevisível, entre o factível e o improvável, laborando sobre o que passa numa aula, no instante imprevisível do presente.
\end{abstract}

Palavras-chave: Docência; Aula; Improvisação.

\section{LABORING TEACHING BETWEEN THE WAITING AND THE PRESENCE: A STUDY OF EDUCATION AS PERFORMANCE}

\begin{abstract}
This text presents teaching from the viewpoint of performance, based on a state of readiness, can enable improvisations in a class. It is about postulating teaching as a practice that deals with events. However, our existence hinges on a culture of meanings, in which creating conditions to produce presences is necessary, since meanings are imposed at all times. We conjecture the waiting as this stratagem. It is a game where teaching performance acts on the threshold between education and art, since it allocates itself in the dialogue between the visible and the unpredictable, between the feasible and the unlikely, laboring on what happens in a class, in the unpredictable moment of the present.
\end{abstract}

Keywords: Teaching; Class; Improvisation.

\footnotetext{
${ }^{2}$ Agência de fomento: Conselho Nacional de Desenvolvimento Científico e Tecnológico - CNPq. O presente trabalho foi realizado com apoio da Coordenação de Aperfeiçoamento de Pessoal de Nível Superior - Brasil (CAPES) - Código de Financiamento 001.

${ }^{3}$ Graduado em Educação Física, licenciatura plena, pela Universidade de Santa Cruz do Sul -UNISC; Mestre em Educação pela Universidade Federal do Rio Grande do Sul - UFRGS; artista e professor de circo, dança e performance.

4 Doutorado em Educação (PPGEDU/UFRGS), Mestrado em Literatura (Teoria literária) PPGL/UFSC), Graduação em Ciências Sociais (CFH/UFSC). Professor no Departamento de Ensino e Currículo e no Programa de Pós-Graduação em Educação da Faculdade de Educação da Universidade Federal do Rio Grande do Sul - UFRGS.
}

ESTEVES, Diego Winck; ADÓ, Máximo Daniel Lamela. Laborar a docência entre espera e presença: um estudo da educação como performance Revista da FUNDARTE. Montenegro, p.01-18, ano 21, no 46, setembro de 2021.

Disponível em: http://seer.fundarte.rs.gov.br/index.php/RevistadaFundarte/issue/archive $>30$ de setembro de 2021. 


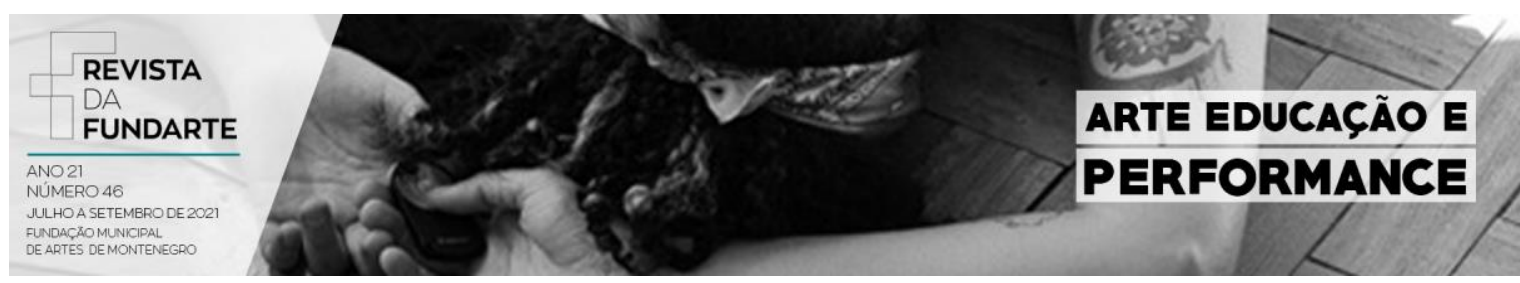

\title{
LABORAR LA DOCENCIA ENTRE ESPERA Y PRESENCIA: UN ESTUDIO DE LA EDUCACIÓN COMO PERFORMANCE
}

\begin{abstract}
Resumen: Este texto propone perspectivar la docencia por la vía de la performance, coloca, como punto de vista, que cierta noción de espera puede condicionar posibilidades para improvisaciones en una clase. Se trata de postular la docencia como un hacer que lidia con acontecimientos. Sin embargo, nuestra existencia se despliega por encima de una cultura de sentidos, en la cual es necesario constituir condiciones para producir presencias, una vez que los sentidos se imponen a todo momento. Conjeturamos la espera como este artificio. Se trata de un juego donde la performance docente opera en el linde entre educación y arte, una vez que se instala en la interlocución entre lo visible y lo imprevisible, entre lo factible y lo improbable, laborando sobre lo que pasa en un aula, en el instante imprevisible del presente.
\end{abstract}

Palabras clave: Docencia; Clase; Improvicación.

\section{Atenção e produção de presença}

Neste texto pretendo perspectivar a improvisação a partir de certa noção de espera. Passo, assim, a pensar o improviso no âmbito dos acontecimentos de uma aula, mas não pela via do que ele faz, ou seja, pela ação de improvisar, e sim, pelo que condiciona a sua realização, isto é: uma estrita relação com um estado de prontidão, processo no qual a espera demanda a atenção numa correlação produtora de presenças, que amplia os impactos das coisas sobre si, nos termos que nos apresenta Gumbrecht (2010, p.13):

\begin{abstract}
Uso "produção" no sentido de sua raiz etimológica (do latim producere), que se refere ao ato de "trazer para diante" um objeto no espaço. [...] Por isso, "produção de presença" aponta para todos os tipos de eventos e processos nos quais se inicia ou se intensifica o impacto dos objetos "presentes" sobre corpos humanos. Todos os objetos disponíveis "em presença" serão chamados, neste livro, "as coisas do mundo".
\end{abstract}

Esperar significa uma ação no âmbito do tempo, de retardar seus atos possíveis, de certa maneira, uma não-ação em proveito de uma intensidade por vir. Pretende-se com isso promover uma espécie de ampliação da sensibilidade para com "as coisas do mundo", no sentido de se estar mais compassivo aos efeitos que

ESTEVES, Diego Winck; ADÓ, Máximo Daniel Lamela. Laborar a docência entre espera e presença: um estudo da educação como performance Revista da FUNDARTE. Montenegro, p.01-18, ano 21, oㅡ 46, setembro de 2021.

Disponível em: http://seer.fundarte.rs.gov.br/index.php/RevistadaFundarte/issue/archive $>30$ de setembro de 2021. 


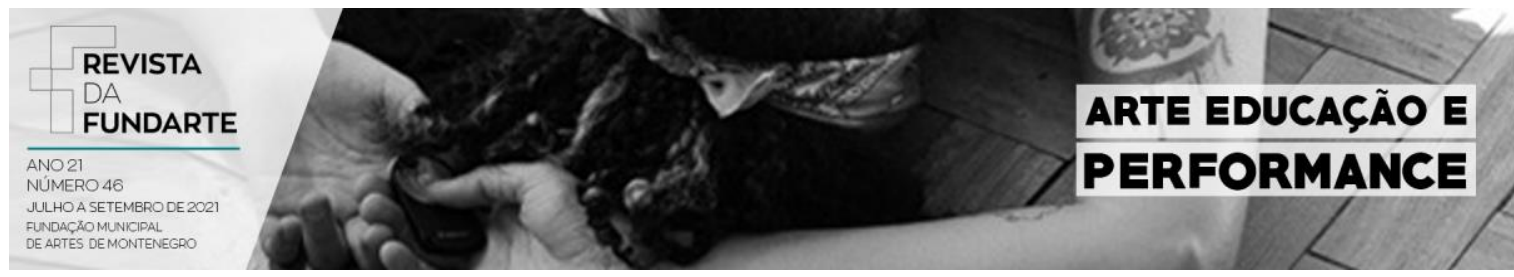

as presenças produzem em si, numa ampliação de impactos. Considera-se, então, que esse estado de espera possa ter efeito sobre a ambiência de uma aula, na qual docente e discentes esperam algo que está por vir; esse algo, por sua vez, poderá ser apropriado como matéria na agência da improvisação, como veremos adiante. Uma aula seria, de antemão, esse espaço de atenção suplementada à matéria de estudo, com uma consciência destacada de si e das coisas, que difere doutros momentos cotidianos: ou seja, na aula pensamos no que fazemos enquanto fazemos o que pensamos; e é essa característica que introduz a esses processos uma qualidade de performance (CARLSON, 2009).

Por essa via - a da consciência das ações manifestas e de seu jogo de visibilidade, neste caso, o da performance docente sob a presença dos discentes, que também performam - colocamos em questão os ritos da/na docência e a possibilidade de tomar a improvisação como um modo de lidar com os imprevistos e o inesperado pela via da potência; portanto, como algo que, paradoxalmente, se espera; assim, tomando os imprevistos como experiência e matérias de uma aula. Interessa-nos, por consequência, pensar a performance como a possibilidade de desviar do que se expecta à priori numa aula, de suas condutas restauradas, em virtude de uma espera alargada em prol do que é imprevisto. Trata-se de estar à espreita do que difere, para que este algo possa produzir efeitos improváveis.

Isto posto, se o professor ao entrar em sala de aula tem de lidar com certa expectativa dos alunos, neste contexto, acreditamos que as pausas, o silêncio, as improvisações, que tomam do inesperado e provocam estranhamentos - inclusive, espantos -, podem vitalizar esse espaço no sentido de produzir um estado de atenção que o improvável tende a nos provocar. Assim, criando a ambiência mencionada anteriormente e fazer da aula mais uma manifestação de arte performática do que um teatro no qual se representam personagens. Vejamos, com Carlson (2010, p.17) esta comparação entre o teatro tradicional e a arte performática moderna:

Seus praticantes [da arte performática moderna], quase por definição, não baseiam seu trabalho em personagens previamente criados por outros

ESTEVES, Diego Winck; ADÓ, Máximo Daniel Lamela. Laborar a docência entre espera e presença: um estudo da educação como performance Revista da FUNDARTE. Montenegro, p.01-18, ano 21, no 46 , setembro de 2021.

Disponível em: http://seer.fundarte.rs.gov.br/index.php/RevistadaFundarte/issue/archive $>30$ de setembro de 2021. 


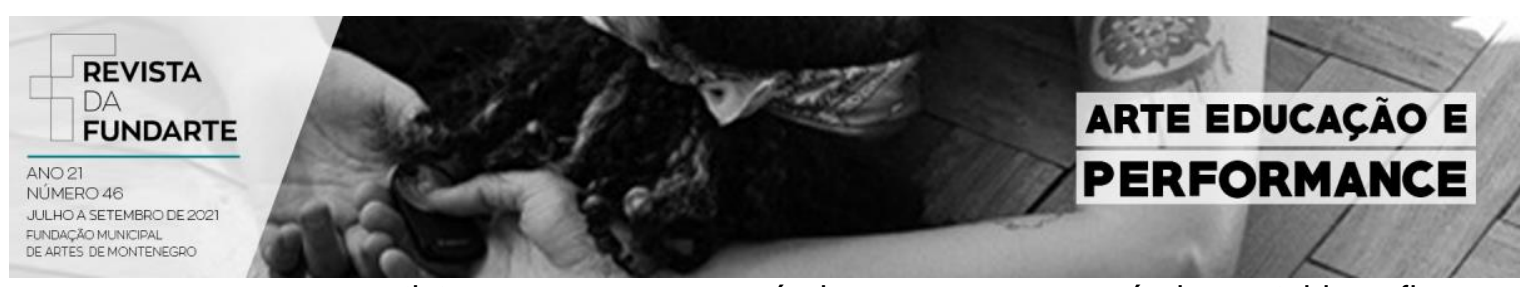

artistas, mas em seus próprios corpos, suas próprias autobiografias, suas próprias experiências, numa cultura ou num mundo que se fizeram performativos pela consciência que tiveram de si e pelo processo de se exibirem para uma audiência. Desde que a ênfase esteja na performance e em como o corpo ou o self é articulado por meio da performance, o corpo individual permanece no centro de tais apresentações.

Quero, para seguir, ponderar que a espera não se faz, necessariamente, em silêncio, imobilidade. Que a digressão, por exemplo, é uma espécie de exercício de escorregar por meio dos enunciados e nisso ir aos poucos se aproximando do objeto de estudo: no caso deste texto, num ensaiar, um exercício de espera em movimento em torno de uma escritura que lida com a improvisação. Assim, o "objeto" de estudo arbitrariamente definido aqui sobre a noção de improviso, almeja tratar dos acontecimentos que escapam numa aula e no próprio fazer da escrita e pensar acerca de como podemos produzi-los, no sentido de trazê-los à frente; logo, considera-se potencializá-los, essa força informe, tendo na improvisação uma ação imediata de compor com isso que passa, improvável, imponderável. Performance de artista-escritor-professor que procura por intermédio da escrita, improvisar com as palavras, e nesse jogo ensaiar possibilidades para fazer do imponderável matéria: matéria improvável, que não se pode, portanto, provar; sem embargo, matérias intempestivas, imanentes, com forças para provocar efeitos de presença e, por conseguinte, de sentidos.

\section{Uma pausa: a primeira pessoa, o pesquisador-docente}

Uma tomada de ar, uma pausa, uma espera em movimento, junto à Barthes (2012, p.416):

A escritura sobrevém quando determinado efeito (contraditório) se produz: que o texto seja ao mesmo tempo um louco dispêndio e uma reserva inflexível - como se, no termo extremo da perda, restasse ainda, inesgotavelmente, alguma coisa retida em vista do texto por vir.

Uma nota pessoal sobre essa espera em movimento: a produção deste texto

ESTEVES, Diego Winck; ADÓ, Máximo Daniel Lamela. Laborar a docência entre espera e presença: um estudo da educação como performance Revista da FUNDARTE. Montenegro, p.01-18, ano 21, no 46, setembro de 2021.

Disponível em: http://seer.fundarte.rs.gov.br/index.php/RevistadaFundarte/issue/archive $>30$ de setembro de 2021 . 


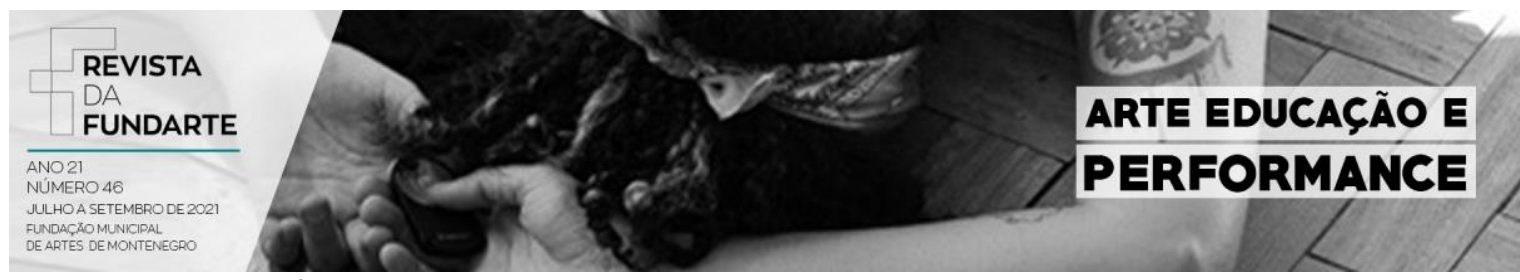

ganha corpo ao final de um processo de pesquisa, embora o plano do texto tenha colocado a relação improviso-docência como centralidade do estudo a que se propunha. Pareceu-me, contudo, no desdobrar deste fazer em torno de uma pesquisa-docência e sua relação com os não-previstos, que outras questões precisavam ser tratadas antes de chegar a este ponto - o da improvisação enquanto uma agência apropriadora de imprevistos, que compõe, poeticamente, diferindo do conhecido previamente e das condutas restauradas. Se impôs a necessidade de ponderar, sobretudo, perspectivando via certas ideias de jogo e de estudo, para que a questão inicial, a da improvisação nos espaços de educação, assim se apresentasse, digo, menos escorregadias.

Ainda que essa escrita da pesquisa tenha se valido de procedimentos para improvisar a si mesma, o tema do improviso, de fato, foi sendo lançado sempre um passo à frente. Talvez, de algum modo, seja essa a força do improviso: nos manter atentos e curiosos com o imprevisível à nossa espera, seguindo em deslocamentos; como um nômade, não subjugar a linha ao ponto, mantendo-se em movimento no qual a espera e as paragens são uma forma de desaceleração, como podemos ler no "Tratado de Nomadologia" de Deleuze e Guattari (1997). A possibilidade de sempre voltar a improvisar, nesses termos, é sedutora, onde as composições enunciam um ponto, um efeito de sentido apropriado pelo improvisador num jogo de presenças (muitas delas imperceptíveis ao intelecto) que seguem na linha contínua da existência.

Chega o momento então de tratar, ao menos com maior atenção, da relação improviso e docência. Todavia, sinto que preciso fazê-lo pela tangente, com a perspicácia de quem observa com atenção, mas sobre certa distância e meio de soslaio: de quem se mantém à espreita do preciso momento da aproximação ao objeto que the seduz, pois, prudente, mensura os riscos de uma abordagem inadequada, demasiado imatura; titubeia assim entre o amor e o temor, algo que parece ser característico das paixões.

Noto, ainda, o se tornar presente na escrita, afirmar a primeira pessoa que diz

ESTEVES, Diego Winck; ADÓ, Máximo Daniel Lamela. Laborar a docência entre espera e presença: um estudo da educação como performance Revista da FUNDARTE. Montenegro, p.01-18, ano 21, no 46, setembro de 2021.

Disponível em: http://seer.fundarte.rs.gov.br/index.php/RevistadaFundarte/issue/archive $>30$ de setembro de 2021. 


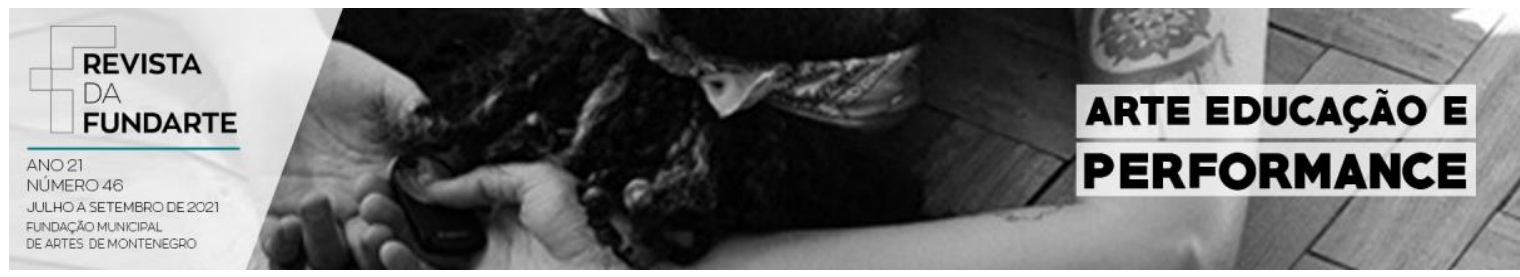

eu, e nisso assumir os movimentos incertos do pesquisar, é dizer-se no escrever, fazendo do texto uma performance, e ter no leitor um espectador. É, de algum modo, dividir a atenção entre o "objeto de estudo" e a si como este que o estuda, pois, no caso da improvisação, um não se dá sem o outro: estamos num jogo de imprevisibilidade, de composições improváveis de antemão. Trata-se, assim, de assumir, ou aceitar, ou escolher, que a própria escrita precisa improvisar-se ao se colocar na periferia do que conhece, para poder escrever com imprevistos, ou seja, como o que não foi "ante-visto".

Desse modo, pela especificidade deste estudo, por tentar circunscrever em torno da improvisação uma relação da Educação com o informe, indefinido, errático, imprevisível e, nisso, encontrar um potencial em seu caráter de estudo - ao contrário de tomar a Educação na centralidade de relações de ensino-aprendizagem sobre um currículo dado - é que me pareceu pertinente se presentificar enquanto este que tenta, que ensaia num improvisar e compor na escrita. Primeira pessoa que aceita os riscos desta abordagem, labiríntica, que se aproxima, ao poucos, em retornos, idas e vindas, ziguezagues: pesquisa que não encontra no erro um impertinente, sobretudo por não ter uma meta, pois sua intenção está na própria procura e nos encontros potenciais. Assim, me chamou atenção esta passagem do livro que é uma espécie de guia neste estudo, Produção de Presença, de Hans Ullrich Gumbrecht (2010, p.17), que diz:

Em parte, sentiu-se [o autor] impelido a escrever desse modo ["autobiográfico"] por pensar que é necessário encontrar um lugar específico para uma tese tão pessoal como a sua (e para o modo como surgiu sua tese) num espaço intelectual de contornos estranhamente imprecisos. [...] Nessas circunstâncias não é possível deixarmos de ser o nosso próprio ambiente intelectual, e acabamos sendo também as referências da obra que nos interessa.

\section{Sobre improvisar a docência}

Colocado, pois, no centro da questão, a espera, ou, como tenho tratado noutros textos: um modo de esperar, um estado de prontidão. Por essa via, a

ESTEVES, Diego Winck; ADÓ, Máximo Daniel Lamela. Laborar a docência entre espera e presença: um estudo da educação como performance Revista da FUNDARTE. Montenegro, p.01-18, ano 21, no 46, setembro de 2021.

Disponível em: http://seer.fundarte.rs.gov.br/index.php/RevistadaFundarte/issue/archive $>30$ de setembro de 2021. 


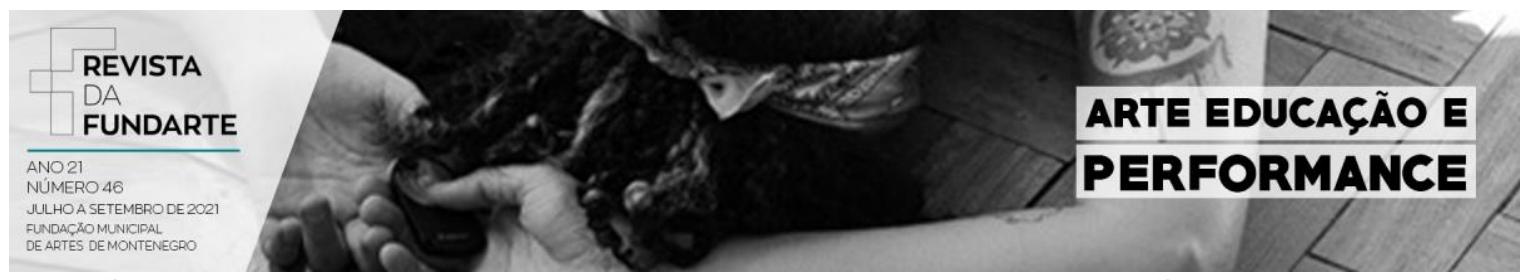

condição para o improviso estaria nesse estado de prontidão, mais do que na técnica, num método, ou nas possibilidades que se apresentam àquele que age à guisa do improviso; para que, a partir deste estado corporal, a improvisação produza efeitos que nos interessam na docência. Trata-se, contudo, de uma atenção dispersa, difusa, um corpo pronto para agir, mas sem um objetivo definido de antemão. Com efeito, não se pode esperar algo em específico ao improvisar: a atenção não pode focar num objeto, precisa estar atenta às possibilidades. Portanto, trata-se de uma atenção com o mínimo de tensão possível, de certa forma multifocal.

De todo modo - e este ponto é de suma importância —, apesar de não lançar mão de fórmulas prontas, o improviso e o próprio estado de prontidão são aprimorados, praticados, treinados. Assim, uma aula que tenha na improvisação um modo de operar (ou uma possibilidade de) considera o planejamento: o docente se prepara, possui um repertório para atuação, não abandona o que sabe e não menospreza o currículo, pois é com este material, também, que improvisa. Conforme nos aponta Coutinho (2018, p.123):

Para im-pro-visar (que etimologicamente significa não-antes-ver $=$ não antever), ao contrário do que se entende no sentido comum, precisa-se, sim, de preparação, mas de maneiras diferentes daquelas geralmente efetivadas na educação formal, que pretendem controlar os processos pedagógicos antecipando (antevendo) o que vai acontecer e situando a organização dos espaços e tempos no centro dessa pretensão.

Portanto, a improvisação não resulta de uma aleatoriedade ou descaso, muito pelo contrário: por lidar com o improvável, com o imprevisível, apropriando-se de um acontecimento num instante passageiro, tal precisão não pode ser senão o ato de um corpo treinado, um corpo que tem consigo um intensivo cuidado. Cabe ressalvar que, embora, no ato de improvisar não se possa antever os resultados, e que a espera da qual estamos tratando não possa objetivar algo do que espera, ou seja, precisa esperar por um momento ou uma coisa qualquer, mas um momento ou coisa

ESTEVES, Diego Winck; ADÓ, Máximo Daniel Lamela. Laborar a docência entre espera e presença: um estudo da educação como performance Revista da FUNDARTE. Montenegro, p.01-18, ano 21, no 46, setembro de 2021.

Disponível em: http://seer.fundarte.rs.gov.br/index.php/RevistadaFundarte/issue/archive $>30$ de setembro de 2021. 


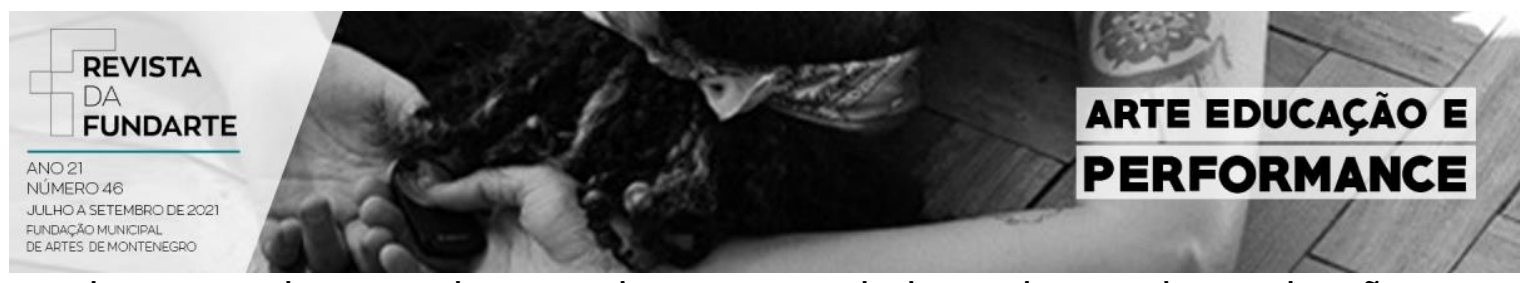

intensivo, que nisso se destaca dos outros; ainda assim, na improvisação tem-se como pressuposto que seus efeitos possam vitalizar os corpos presentes nos encontros de uma aula. Se há algo que se espera, que se expecta, se há, então, um objetivo da improvisação, seria, para tomar de Espinosa (DELEUZE, 2002), aumentar nosso potencial para agir no mundo.

Esse estado de prontidão, que em outros textos defini, ao menos provisoriamente, como Estado de Improviso, precisa ser perspectivado com um estado de jogo, ou, como melhor parece funcionar nesse estudo (ou como mais me seduz), na leitura que Bataille (2017) faz em Nietzsche, como Vontade de Chance, que está em tensão com a ideia, destacada em outros filósofos, de Vontade de Potência. Portanto, o Estado de Improviso é esse estado de espera que condiciona a improvisação como um ato, como a efetuação que tem como condição de sua eficiência um estado de prontidão para improvisar, para agenciar(se) com as matérias em jogo nas contingências espaço-temporais; trata-se de um ato instantâneo, imediato. Sendo assim, a condição de possibilidade para a improvisação está num corpo impactado pelas coisas do mundo, mas também pelo que de imponderável passa entre e sobre elas; preparado para agir neste entre: um corpo em jogo que tem em vista as chances, os possíveis. Reforçamos essa ideia, então, com Bataille (2017, p.133):

É fácil para mim ver agora o que desvia cada homem do possível, ou, querendo, o que desvia o homem de si mesmo. O possível, de fato, não é mais do que uma chance - que não podemos agarrar sem perigo. A outra opção seria aceitar a vida morna e ver como um perigo a verdade da vida que é a chance. A chance é um fator de rivalidade, uma impudência. Daí o ódio pelo sublime, a afirmação da terra a terra ad unguem e o temor do ridículo (dos sentimentos raros, em que esbarramos, que temos medo de ter).

Recordo-me, no que este estado de prontidão como uma postura em jogo para a chance tem de semelhanças com a imagem do combate, de uma citação que teve importância para os estudos que antecederam a este, e que me parece ter muito a

ESTEVES, Diego Winck; ADÓ, Máximo Daniel Lamela. Laborar a docência entre espera e presença: um estudo da educação como performance Revista da FUNDARTE. Montenegro, p.01-18, ano 21, no 46, setembro de 2021.

Disponível em: http://seer.fundarte.rs.gov.br/index.php/RevistadaFundarte/issue/archive $>30$ de setembro de 2021. 


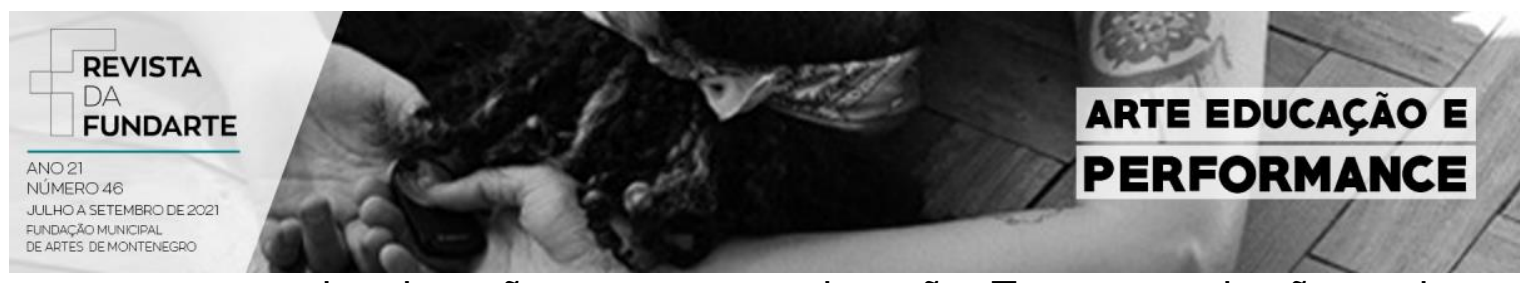

acrescentar nesta interlocução entre arte e educação. Tomo esta citação no decurso da minha história pessoal com a arte marcial Taekwondo, da qual fui professor dos quinze aos vinte e três anos, com o primeiro contato aos nove anos de idade. Tratase do livro Sabedoria Incomum, de Fritjof Capra, que penso pode nos ajudar a definir esse estado de prontidão, num relato pessoal do autor, e no que este fragmento se associa com a ideia de um guerreiro que não age, para, paradoxalmente, poder agir:

Naquela época, minha vida e meu estilo de trabalho estavam sobre forte influência da filosofia taoísta. Buscava intensificar minha percepção intuitiva e reconhecer "os padrões do taoísmo"; praticava a arte do wu wei, o não agir que vai "contra o feitio das coisas", esperando pelo momento certo sem forçar nada. A metáfora de Castañeda, do centímetro cúbico de chance que desponta de tempos em tempos e é apanhado pelo "guerreiro" que leva uma vida disciplinada e que aguçou sua intuição, estava sempre presente em minha mente (2009, p.75).

Para finalizar este trecho, proponho uma mistura improvável como uma imagem para a docência: um guerreiro-palhaço. Guerreiro que combate, antes, a si mesmo: a moralização no pensamento, os pressupostos de qualidade de eficiência em seu fazer, os juízos de certo e errado, e, entre outras coisas, a hegemonia dos sentidos. Noutros termos, combate a realidade dominante, deveras pesada, moralista, calcada nos movimentos de representação, de interpretações que buscam sempre um sentido anterior, um "antes-visto" nos imprevistos que emergem a cada instante. Mas tal guerreiro precisa se aliar ao palhaço, vestir sua máscara, usar da própria ação de interpretar os acontecimentos, mas não para voltar atrás, para rever, e sim para seguir, com uma grande gargalhada, inventando e compondo realidades possíveis. Logo, se lida com um arquivo, se utiliza um repertório para mobilizar os humores, mais do que uma pré-ocupação com os sentidos: um professor-guerreiropalhaço que convida para o improviso do combate, para fazer o corpo agir numa aula - como chance, não como objetivo - tensionado pelas presenças, incômodas e perigosas, mas, sobretudo, sedutoras. Por consequência, tensionando o pensar no pensamento, sem nunca esquecer o quanto somos, todos, ridículos: ou seja,

ESTEVES, Diego Winck; ADÓ, Máximo Daniel Lamela. Laborar a docência entre espera e presença: um estudo da educação como performance Revista da FUNDARTE. Montenegro, p.01-18, ano 21, no 46, setembro de 2021.

Disponível em: http://seer.fundarte.rs.gov.br/index.php/RevistadaFundarte/issue/archive $>30$ de setembro de 2021. 


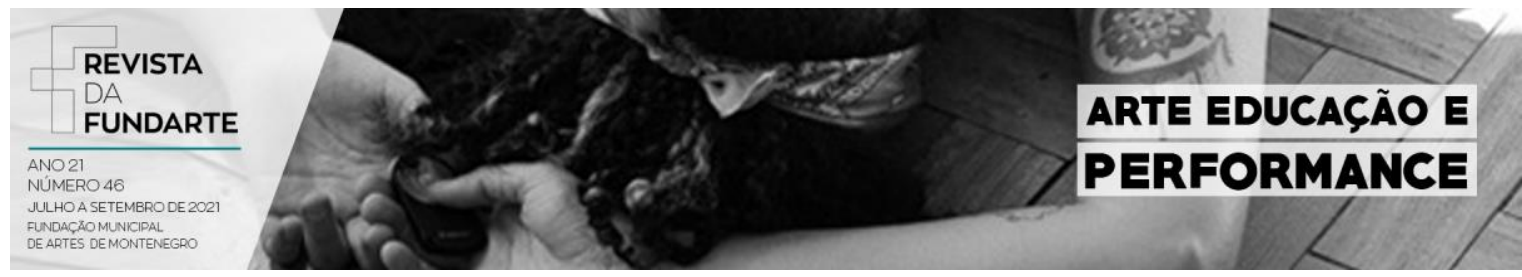

passíveis de riso. Colocamo-nos em jogo de imprevisibilidade:

Quem quer que sejas, tu que me lês: joga tua chance. Como eu faço, sem pressa, assim como no instante em que escrevo, eu te jogo. Essa chance não é tua nem minha. Ela é chance de todos os homens e sua luz. [...] Mas jogar é, em primeiro lugar, não levar a sério. E morrer... A afirmação particular, ao lado do jogo, da chance, parece vazia e inoportuna. É pena limitar aquilo que, por essência, é ilimitado: a chance, o jogo. (BATAILLE, 2017, p.129).

Cabe lembrar o sentido de conquista da liberdade em Nietzsche (2005): jamais se envergonhar de si próprio! Esta noção de liberdade, portanto, pode ser nosso guia, enquanto nos colocamos em jogo, em chance, nos espaços de Educação.

\section{Numa aula: entre presenças e sentidos}

Seguimos, então, ou retornamos, com Gumbrecht, num ponto que é imprescindível para este estudo: a tensão entre os efeitos de sentido e efeitos de presença, com o destaque para o caráter efêmero do segundo:

Para nós, os fenômenos de presença não podem deixar de ser efêmeros, não podem deixar de ser aquilo que chamo de "efeitos de presença"; numa cultura que é predominantemente uma cultura de sentidos, só podemos encontrar esses efeitos. Para nós, os fenômenos de presença surgem sempre como "efeitos de presença" porque estão necessariamente rodeados de, embrulhados em, e talvez até mediados por nuvens e almofadas de sentidos. É muito difícil - talvez até impossível - não "ler", não tentar atribuir sentido àquele relâmpago ou àquele brilho ofuscante do Sol da Califórnia. (GUMBRECHT, 2010, p.135).

A improvisação aparece então como um exercício de se colocar em jogo entre efeitos de sentido e efeitos de presença. Se, portanto, estamos desde sempre nessa tensão - por ser esse um efeito da nossa cultura, na qual prevalece o sentido cabe ponderar que a improvisação e, sobretudo, a espera que a condiciona, é um

ESTEVES, Diego Winck; ADÓ, Máximo Daniel Lamela. Laborar a docência entre espera e presença: um estudo da educação como performance Revista da FUNDARTE. Montenegro, p.01-18, ano 21, oㅡ 46, setembro de 2021.

Disponível em: http://seer.fundarte.rs.gov.br/index.php/RevistadaFundarte/issue/archive $>30$ de setembro de 2021. 


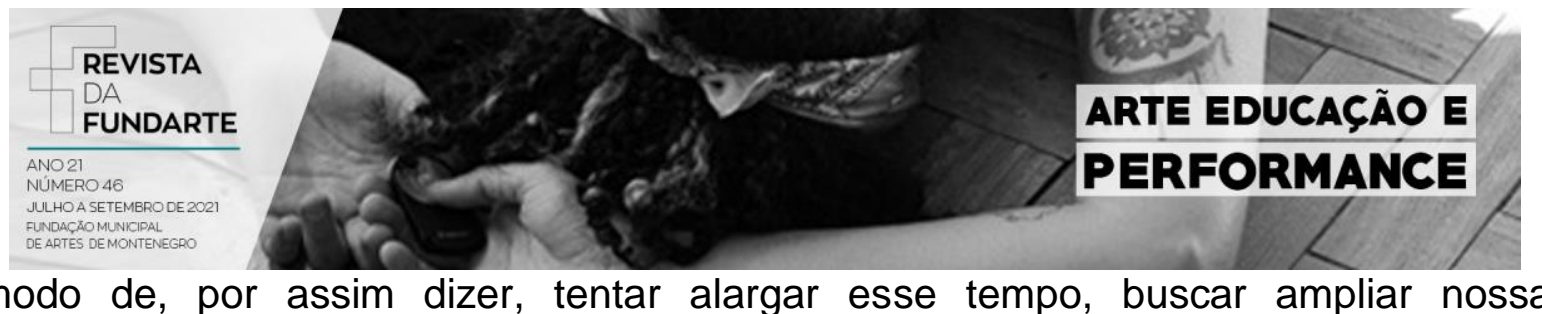

percepção para com essa tensão, tendo em vista, o impacto das coisas do mundo sobre si; de se colocar, nas palavras de Gumbrecht (2010, p.137), no meio do desassossego:

\begin{abstract}
A relação entre efeitos de presença e efeitos de sentido também não é uma relação de complementariedade, na qual uma função atribuída a cada uma das partes em relação à outra daria à copresença das duas a estabilidade de um padrão estrutural. Ao contrário, podemos dizer que a tensão/oscilação entre efeitos de presença e efeitos de sentido dota o objeto de experiência estética de um componente provocador de instabilidade e desassossego.
\end{abstract}

Tal espera significa uma tentativa de desviar do sentido mais imediato que diz "o que a coisa é", de resistir a uma espécie de conduta restaurada sobre as matérias, que não são inertes, considerando, então, que as coisas em si possuem potencial agenciador. Trata-se de permanecer à espreita de seus efeitos de presença, o que significa, como sujeito, submergir na própria presença de si: como um guerreiro zen em não-ação, reduzindo seu controle centrado e colocando-se assim na periferia de si; permanecer na tangente do desconhecido, na emergência da efetuação de um golpe que ataca o acaso, mas não um ataque qualquer, não um acaso qualquer.

Nesse sentido, é que tenho proposto perspectivar a improvisação nesse jogo tensional entre um "dentro" e um fora, pois, em que pese certos estudos tomam a improvisação numa relação com o espontâneo, como uma expressão de si, de espontaneidade, portanto - a exemplo dos estudos de Viola Spolin ${ }^{5}$-, nossa proposição é uma afirmação de um jogo entre o que vem "de fora", tomados aqui

\footnotetext{
5 Citamos como exemplo o livro Improvisação para o Teatro, no qual ela afirma: "Os próprios jogadores criavam suas cenas sem o benefício de um dramaturgo ou de exemplos dados pelo professor-diretor, enquanto era libertados para receber as convenções do palco. [...] Eles podiam colocar toda a espontaneidade para trabalhar ao criar cenas após cenas de material novo. Envolvidos com a estrutura e concentrados na solução de um problema diferente em cada exercício, eles abandonavam gradualmente seus comportamentos mecânicos, emoções, etc., e entravam na realidade do palco, livre e naturalmente, especializados em técnicas improvisacionais e preparados para assumir quaisquer papéis em peças escritas" (SPOLIN, 2015, p.28).
}

ESTEVES, Diego Winck; ADÓ, Máximo Daniel Lamela. Laborar a docência entre espera e presença: um estudo da educação como performance Revista da FUNDARTE. Montenegro, p.01-18, ano 21, ํo 46, setembro de 2021.

Disponível em: http://seer.fundarte.rs.gov.br/index.php/RevistadaFundarte/issue/archive $>30$ de setembro de 2021. 


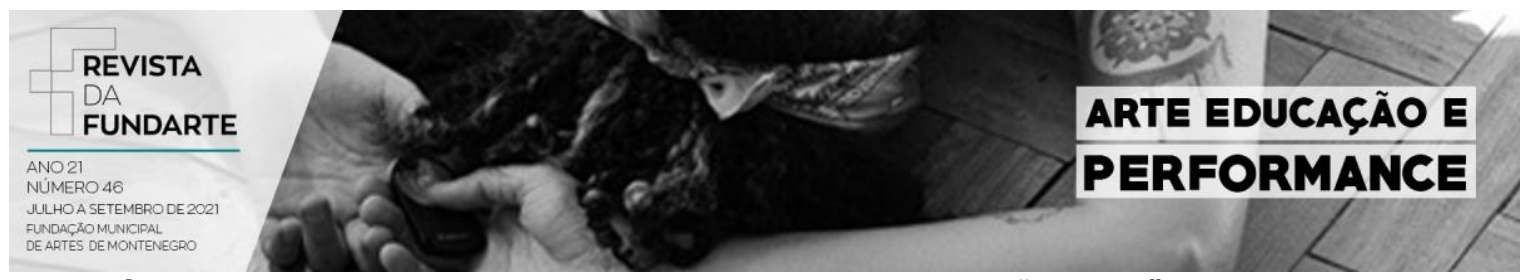

como efeitos de presença, enquanto lidamos com um "dentro" repleto de sentidos, via recognição. Importância da espera: exercícios de contenção para produzir o alargamento deste momento no qual algo não está dado, não está definido — ou melhor, em que tudo ainda está por ser dado, pois os dados não foram jogados.

Espera produtora de intensidades, ou como condição para percebê-las. Vontade de Chance: estar em jogo tendo sempre em mente, com Nietzsche, que o acaso é soberano (DELEUZE, 1976). Assim, na improvisação que parte dessa espera, ou melhor, que tem na espera uma espécie de etapa do improviso, atuamos num momento alheio a nossa arbitrariedade pessoal: agimos, com precisão, sem saber por que ou para que (a ação sabe), para depois, somente depois, pensar sobre. Essa intensidade parece vir do nada, e a improvisação pode ser assim perspectivada em relação à epifania, tal como nos apresenta Gumbrecht (2010, p.141):

Sob o título "epifania" pretendo comentar três características que moldam a maneira como se apresenta diante de nós a tensão entre presença e sentido: pretendo comentar a impressão de que a tensão entre presença e sentido, quando ocorre, surge do nada; a emergência dessa tensão como tendo uma articulação espacial; a possibilidade de descrever sua temporalidade como um "evento".

O autor assim chega numa citação de Heidegger, que nos interessa para encaminhar este texto ao fim, na relação entre a emergência da improvisação, como um "evento" (que neste texto é abarcado na ideia de acontecimento), relacionando-a com a "epifania" de Gumbrecht. Por conseguinte, como uma verdade que emerge sem o filtro do sujeito soberano, sendo esse posto à prova no jogo de improvisar. De acordo com Heidegger: “ $A$ arte, então, é o surgir e o acontecer da verdade. Então, a verdade aparecerá do nada? De fato, assim é, se por nada se entender a mera negação do que é, e se aqui pensarmos no que é como um objeto presente da maneira comum" (HEIDEGGER apud GUMBRECHT, 2010, p.141; grifo do autor).

ESTEVES, Diego Winck; ADÓ, Máximo Daniel Lamela. Laborar a docência entre espera e presença: um estudo da educação como performance Revista da FUNDARTE. Montenegro, p.01-18, ano 21, no 46, setembro de 2021.

Disponível em: http://seer.fundarte.rs.gov.br/index.php/RevistadaFundarte/issue/archive $>30$ de setembro de 2021. 


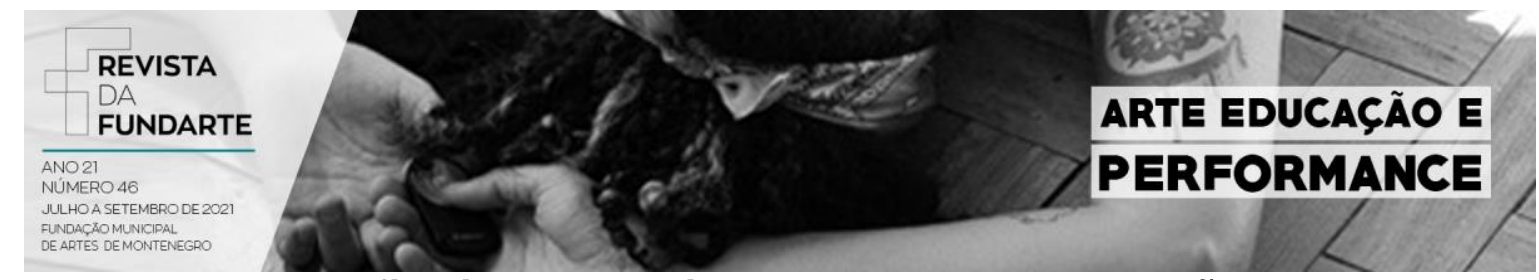

Uma nota antes de finalizar: por cuidado, pontuar uma questão

Importa perspectivar que "a mera negação do que é", ou seja, da negação "do objeto presente de maneira comum", pode resultar numa tendência nada improvável: a da projeção à transcendência. Contudo, apesar de nossa insistência em encontrar maneiras para que nosso corpo possa estar disposto e impactado pelas coisas do mundo, a transcendência não é necessariamente uma inimiga. Pois, sem ao menos a ideia de transcendente, o não-sentido da presença seria, talvez, insuportável. Ainda, cabe perguntar, se pode a presença resguardar em si um tanto de transcendência? Não seria, contudo, um além-mundo, mas uma espécie de transcendência imanente; mas, parece-nos que essa abordagem não nos leva a lugar algum. De modo análogo, Bataille (2017, p.87), coloca a questão: "Deus me parece uma resposta não menos vazia do que a 'natureza' do materialismo grosseiro".

Não desanimemos: podemos encontrar pistas para tratar desta questão - a ser desdobrada em estudos futuros —, na ideia de empirismo transcendental, de Deleuze. Trata-se de perceber que há um limite, e que nele há um potencial (ou potenciais): de ser tomado, enquanto ser em jogo na improvisação, pela força dos encontros, guiado por uma vontade de potência, diante do eterno retorno nietzscheano; de conjecturar que a diferença está em jogo com uma dimensão transcendental. Vejamos, nas palavras de Roberto Machado (2009, p.144):

\footnotetext{
A concepção deleuziana de limite como potência e enésima potência inspira-se diretamente em sua interpretação dos conceitos nietzschianos de vontade de potência, considerado como princípio diferencial e genético, e de eterno retorno, pensado como ser da diferença. Denominar a intensidade "ser do sensível" já era uma referência à vontade de potência e ao eterno retorno. Pois, na interpretação deleuziana de Nietzsche, o eterno retorno não é qualitativo nem extensivo: é intensivo. $E$ isso ele diz explicitamente em Diferença e repetição: "O eterno retorno não cessa de fremir nessa outra dimensão, a do transcendental ou do spatium vulcânico"; ou então: "O eterno retorno nem é qualitativo nem extensivo; ele é intensivo, puramente intensivo. Isto é: ele se diz da diferença. Esse é o liame fundamental entre o eterno retorno e a vontade de potência. Um não pode ser dito a não ser do outro".
}

ESTEVES, Diego Winck; ADÓ, Máximo Daniel Lamela. Laborar a docência entre espera e presença: um estudo da educação como performance Revista da FUNDARTE. Montenegro, p.01-18, ano 21, no 46, setembro de 2021.

Disponível em: http://seer.fundarte.rs.gov.br/index.php/RevistadaFundarte/issue/archive $>30$ de setembro de 2021. 


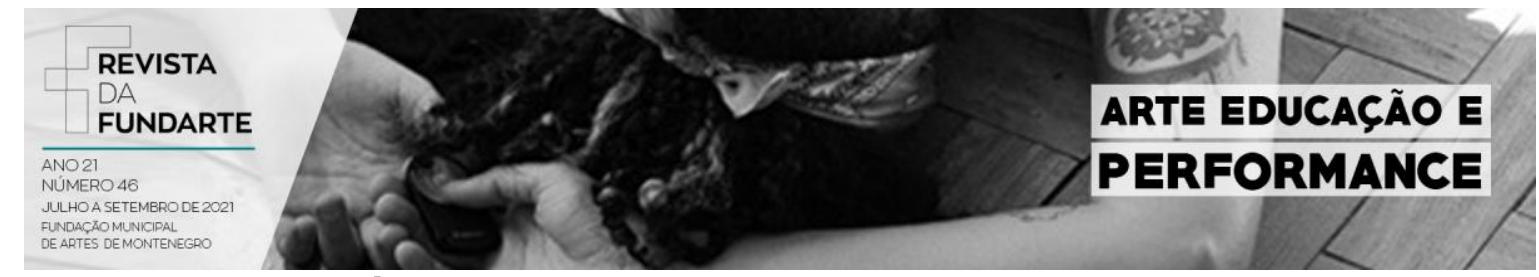

Sobre a porta: a saída, uma entrada

Estamos, inevitavelmente, no desassossego concernente à tensão entre uma espécie de vontade de presença e a necessidade de sentidos; no limite imponderável onde uma coisa se transforma na outra; onde, sem embargo, supomos estar a chance, o potencial. Neste limiar, a arte apresenta sua eficácia em termos de produção se aproximando e até se confundindo com a educação, que passa então a ser compreendida como uma poética da existência em jogo entre as forças das presenças e a necessidade da produção de sentidos para nossos próprios fins humanos - ainda que, demasiado humanos. Cabe notar que nosso interesse maior está neste impreciso momento da metamorfose, da presença que dá a ver um sentido, ou vice-versa. Por suposto, não se trata de um trânsito com vias e direções definidas, mais provável imaginá-lo como uma multidão que se desloca num espaço de passagem, cada qual se perguntando e respondendo, um na cabeça do outro, o que se está fazendo, para onde se está indo, quem se é, enquanto não param de passar.

A espera, intuo, é um modo de se atentar para essa tensão, para as presenças, para os sentidos que se impõem. Assim, desta simultaneidade do jogo entre presença e sentido, proponho a improvisação como uma via poética para a docência, afinal, "a poesia talvez seja o exemplo mais forte da simultaneidade dos efeitos de presença e dos efeitos de sentido" (GUMBRECHT, 2010, p.39). Por falar em poesia, me recordo de Alberto Caeiro:

\footnotetext{
O único sentido íntimo das cousas

É elas não terem sentido íntimo nenhum.

Não acredito em Deus porque nunca o vi.

Se ele quisesse que eu acreditasse nele,

Sem dúvida que viria falar comigo
}

ESTEVES, Diego Winck; ADÓ, Máximo Daniel Lamela. Laborar a docência entre espera e presença: um estudo da educação como performance Revista da FUNDARTE. Montenegro, p.01-18, ano 21, no 46, setembro de 2021.

Disponível em: http://seer.fundarte.rs.gov.br/index.php/RevistadaFundarte/issue/archive $>30$ de setembro de 2021. 


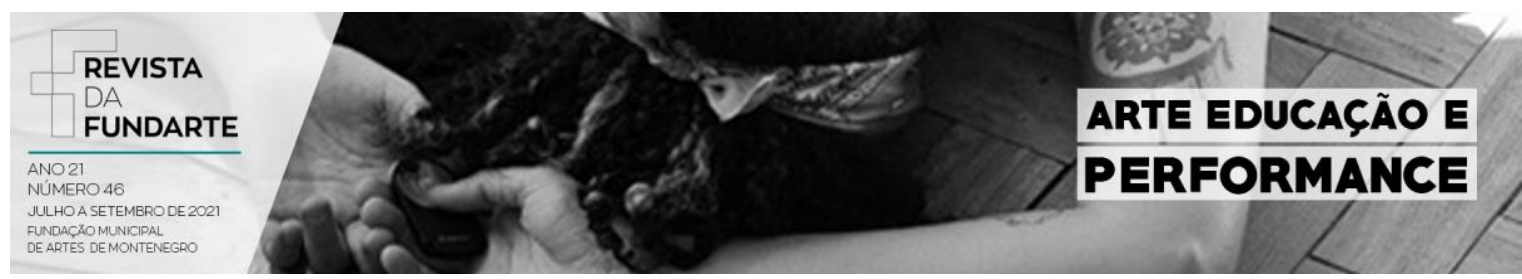

E entraria pela minha porta dentro Dizendo-me,

Aqui estou! (PESSOA, 2005, p.24).

Guardar, então, na contingência da espera, via uma emergência dos possíveis, a força eminente do improvável, significa acolher, sem embargo, a improbabilidade divina, o transcendental, pois a porta está ali, presente. Uma ressalva: neste ponto o não acreditar difere da negação, pois, não dar crédito a algo supõe a possibilidade ética da sua existência. Trata-se de não conferir ao transcendente o destino, todavia, não de negá-lo: se o sujeito não é mais soberano, também não é o transcendente, tampouco Deus; contudo, ambos são possíveis, e não importa tanto a factibilidade de sua existência, mas que, enquanto ideias, produzem efeitos sobre nossa realidade.

Inserir Deus, novamente, após sua morte ter sido anunciada por Nietzsche (2005) há mais de um século atrás é, sem dúvidas, um pensamento insensato. Ora, pois, estamos a considerar uma epifania, tal como parece chegar à Bataille (2017, p.88), no decurso de seus questionamentos:

\begin{abstract}
Veio o momento em que, minha audácia - se quiserem, minha desenvoltura - propondo-me: "Você não poderia ter, você mesmo, essa experiência insensata — depois rir dela?", respondi: "Impossível: não tenho a fé!". No silêncio em que estava, num estado de disponibilidade verdadeiramente louca - eu permanecia debruçado sobre o vazio - tudo me pareceu igualmente risível, hediondo, possível... Nesse momento, segui adiante. Imediatamente, reconheci Deus.
\end{abstract}

Assim, então, encaminhamos este texto ao final. Partimos, no início, de uma perspectivação da docência como performance, na acepção de uma conduta restaurada. Restauração operada, entre outras coisas, pela força gravitacional do currículo que lhe condiciona as formas e a métrica. Currículo que nos oferece, a nós, docentes, o "o que é", um mundo, o "objeto presente da maneira comum". Mas, se não há sentido íntimo das coisas, como nos diz Pessoa (e Nietzsche), muito menos haveria um sentido comum das coisas. Não se trata de travar uma batalha contra o

ESTEVES, Diego Winck; ADÓ, Máximo Daniel Lamela. Laborar a docência entre espera e presença: um estudo da educação como performance Revista da FUNDARTE. Montenegro, p.01-18, ano 21, no 46, setembro de 2021.

Disponível em: http://seer.fundarte.rs.gov.br/index.php/RevistadaFundarte/issue/archive > 30 de setembro de 2021. 


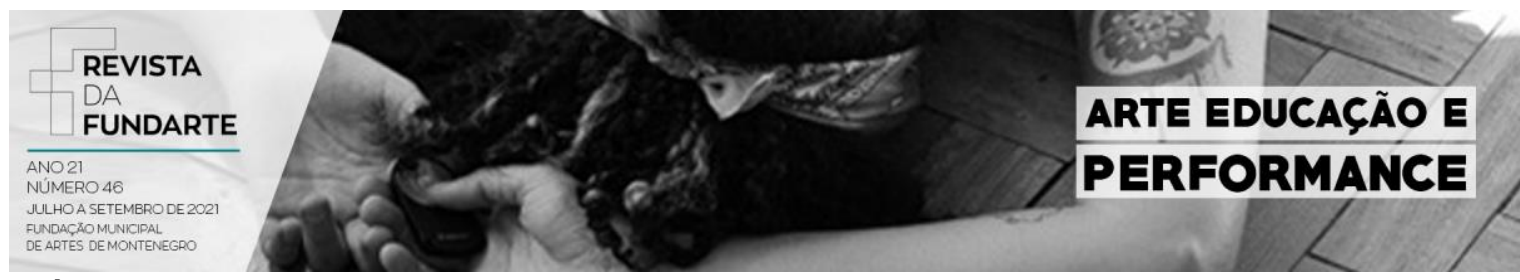

currículo, contra a escola, contra a universidade, de assumir uma postura de resistência ressentida, mas de produzir pequenos desvios, aqui e ali, acessos intermitentes de improvisação. Uma aula exige preparação, rigor, planejamento: é preciso uma rota para ter do que se desviar. Trata-se de considerar que a espera, como suspensão da ação, é uma possibilidade de resistir às posturas que definem o "o que é" um professor, um currículo, uma aula. Possibilita perceber os momentos nos quais cabem pequenas variações sobre o que era esperado, valorizando a presença do que antes estava ausente, por ausência de atenção, de apreensão. São, com efeito, tomadas de imprevistos, chegadas ao acaso do improvável: um olhar, um gesto, uma escuta, uma palavra, um riso, como um Deus que entra pela porta, dançando!

Afinal, "afora a liberdade, o próprio riso, não há nada de que eu ria menos divinamente do que de Deus" (BATAILLE, 2017, p.88).

\section{Referências:}

BATAILLE, Georges. Sobre Nietzsche: vontade de chance. Tradução Fernando Scheibe. Belo Horizonte: Autêntica, 2017.

BARTHES, Roland. Au Séminaire. In. O Rumor da Língua. São Paulo: Martins Fontes, 2012.

CAPRA, Fritjof. Sabedoria Incomum. Tradução Carlos Afonso Malferrari. São Paulo: Cultrix, 2009.

CARLSON, Marvin. Performance: uma introdução crítica. Minas Gerais: Editora UFMG, 210.

COUTINHO, Karyne. Por uma didádica da improvisação. Revista Em Aberto, Brasília, v.31, n.101, p.121-132, jan/abr. 2018.

DELEUZE, Gilles. Espinosa: Filosofia Prática. Tradução Daniel Lins e Fabien Pascal Lins. São Paulo: Escuta, 2002.

DELEUZE, Gilles. Nietzsche e a Filosofia. Tradução Edmundo Fernandes Dias e Ruth Joffily Dias. Rio de Janeiro: Editora Rio, 1976.

ESTEVES, Diego Winck; ADÓ, Máximo Daniel Lamela. Laborar a docência entre espera e presença: um estudo da educação como performance Revista da FUNDARTE. Montenegro, p.01-18, ano 21, no 46, setembro de 2021.

Disponível em: http://seer.fundarte.rs.gov.br/index.php/RevistadaFundarte/issue/archive $>30$ de setembro de 2021. 


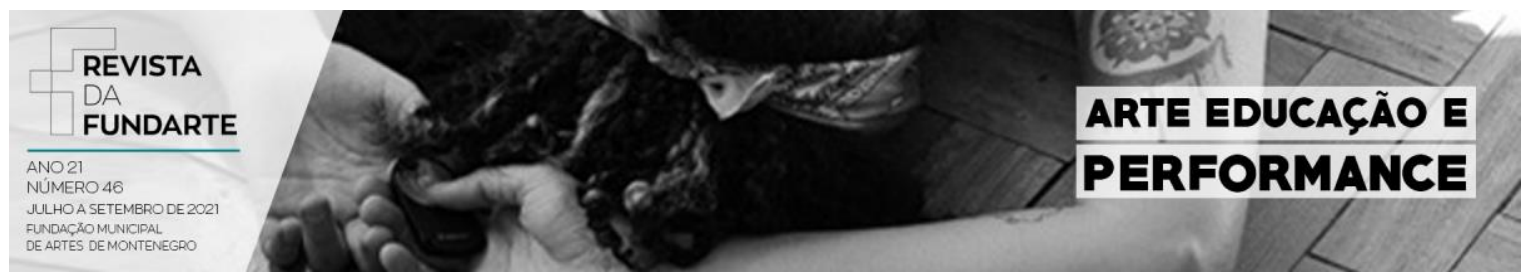

DELEUZE, Gilles; GUATTARI, Félix. Mil Platôs, vol.5. Tradução de Peter Pál Pelbart e Janice Caiafa. São Paulo: Editora 34, 1997.

GUMBRECHT, Hans Ulrich. Produção de presença: o que o sentido não consegue transmitir. Rio de janeiro: Contraponto: Ed. PUC-Rio, 2010.

NIETZSCHE, Friedrich. A Gaia Ciência. Tradução Jean Melville. São Paulo: Editora Martin Claret, 2005.

MACHADO, Roberto. Deleuze, a arte e filosofia. Rio de Janeiro: Zahar, 2009.

PESSOA, Fernando. Alberto Caeiro, Poesias Completas. São Paulo: Companhia das Letras, 2005.

SPOLIN, Viola. Improvisação para o Teatro. Tradução Ingrid Dormien Koudela e Eduardo José de Almeida Amos. São Paulo: Perspectiva, 2015

ESTEVES, Diego Winck; ADÓ, Máximo Daniel Lamela. Laborar a docência entre espera e presença: um estudo da educação como performance Revista da FUNDARTE. Montenegro, p.01-18, ano 21, no 46, setembro de 2021 .

Disponível em: http://seer.fundarte.rs.gov.br/index.php/RevistadaFundarte/issue/archive > 30 de setembro de 2021. 